\title{
Expression of epidermal growth factor receptor is an independent prognostic factor for esophageal squamous cell carcinoma
}

\author{
Qifeng Wang ${ }^{1,5+}$, Hongxia Zhu ${ }^{2 \dagger}$, Zefen Xiao ${ }^{1 *}$, Wencheng Zhang ${ }^{1}$, Xiao Liu ${ }^{1}$, Xun Zhang ${ }^{3}$, Jie He ${ }^{4 *}$, Kelin Sun ${ }^{4}$, \\ Lvhua Wang ${ }^{1}$ and Ningzhi $\mathrm{Xu}^{2}$
}

\begin{abstract}
Background: The overall survival of patients with esophageal squamous cell carcinoma (ESCC) remains poor. Prognostic predictions in ESCC are usually based on histological assessment of tumor invasion and lymph node metastasis, but a biomarker with better predictive accuracy could be more useful. Because overexpression of epidermal growth factor receptor (EGFR) has been associated with poor prognosis, this study investigated whether EGFR is an independent prognostic factor for overall survival and disease-free survival of ESCC patients.

Methods: ESCC tissue specimens from 243 patients obtained during surgical resection between 1980 and 1997 were retrieved for immunohistochemical analysis of EGFR expression.

Results: The data showed that EGFR protein was overexpressed in 187 of 243 (77\%) ESCC tissues. Elevated expression was associated with higher pathologic tumor stages $(P=0.001)$, lymph node metastasis $(P=0.002)$, and higher Union for International Cancer Control (UICC) stage $(P<0.0001)$, as well as poorer disease-free survival and overall survival of ESCC patients $(P<0.0001)$. A multivariate analysis showed that overexpression of EGFR protein was an independent factor for disease-free survival $(P=0.003)$ and overall survival $(P=0.001)$ of these patients. Subgroup analysis of patients with stage IIA (UICC 2002) showed that EGFR overexpression was associated with poorer disease-free survival $(P=0.007)$ and overall survival $(P=0.010)$ of the patients in univariate analyses.

Conclusions: The current study demonstrated that EGFR overexpression was an independent prognostic factor for overall survival and disease-free survival of ESCC patients. However, targeting of EGFR activity using gefitinib or erlotinib could be useful for clinical treatment of ESCC patients.
\end{abstract}

Keywords: Esophageal cancer, Esophageal surgery, Operations, Statistics, Survival analysis, Tumor markers, Fiducial markers

\section{Background}

Esophageal cancer is a significant worldwide health problem, the sixth most frequent cause of cancer death [1,2]. Surgery remains the primary treatment, but in most cases diagnosis is not determined until after surgery is

\footnotetext{
* Correspondence: xiaozefen@sina.com; prof.hejie@263.com

${ }^{\dagger}$ Equal contributors

'Department of Radiation Oncology, Cancer Institute and Hospital, Chinese Academy of Medical Sciences (CAMS) and Peking Union Medical College (PUMC), No.17, Nanli, Panjiayuan, Beijing 100021, People's Republic of China ${ }^{4}$ Department of Thoracic Surgery, Cancer Institute and Hospital, Chinese Academy of Medical Sciences (CAMS) and Peking Union Medical College (PUMC), No.17, Nanli, Panjiayuan, Beijing 100021, People's Republic of China Full list of author information is available at the end of the article
}

feasible. Depending on the type of surgery, the five-year survival rate is $15 \%$ to $37.8 \%$ [3,4]. Studies have shown that prognosis is affected by the number of metastatic lymph nodes [5-7]. Post-surgery pathological studies have confirmed this and have also confirmed an inverse association between survival and the depth of tumor invasion $[8,9]$.

Predictions of post-surgery prognosis are usually based on the Union for International Cancer Control (UICC)/ American Joint Committee on Cancer (AJCC) clinical staging system $[8,9]$. However, determination of tumor stage in esophageal cancer is often imprecise making survival of patients difficult to predict, especially those in the

\section{Biomed Central}


late stages. Thus, there is a need to develop and evaluate biomarkers for predicting survival and treatment response in esophageal cancer.

Elevated levels of epidermal growth factor receptor (EGFR), or increased expression of the EGFR gene, have been reported in a number of human cancers of epithelial origin, including head and neck [10], thyroid [11], breast [12], and colon [13,14] cancers. In a subset of these cancers, most notably breast [15], colorectal [13,14], and esophageal cancers $[16,17]$, increased EGFR expression has been associated with advanced disease, tumor metastases, and poor prognosis.

In developed countries, two-thirds of esophageal cancers are adenocarcinoma, but in most of the world, including China, 95\% are esophageal squamous cell carcinoma (ESCC) $[1,2,18]$. In the current retrospective study of cases occurring between 1980 and 1997 at Cancer Hospital, Chinese Academy of Medical Science, we investigated whether EGFR can serve as an independent prognostic factor for overall and disease-free survival of ESCC patients. Associations between EGFR expression in ESCC tissue specimens and patients' followup data were analyzed.

\section{Methods}

\section{Study population}

In this retrospective cohort study, we retrieved the medical records of 243 patients who had undergone esophagectomy for ESCC, without any pre-surgical neoadjuvant or adjuvant chemotherapy or chemoradiotherapy, between 1980 and 1997 at Cancer Hospital, Chinese Academy of Medical Science. These patients had a clinically localized ESCC, including 23, 92, 68, 28, and 32 patients with stage IB, II, IIIA, IIIB, and IIIC disease, respectively, based on the definitions of the UICC 2010 version [9]. Paraffin-embedded tissue specimens were retrieved from the Pathology Department and prepared for construction of tissue microarray and cut into $4 \mu \mathrm{m}$-thick sections for immunohistochemistry.

As reported previously [5], for tumor in the upper third of the thoracic segment surgeons performed a three-phase thoraco-abdominal McKeown resection via a right thoracotomy, using the stomach for esophageal replacement. For lesions in the mid and lower third, esophagectomy was performed on the left side using the stomach to establish digestive continuation. In each case, lymph nodes were removed as completely as possible. Juxtatumoral, paraesophageal, superior gastric, left gastric, and paracardial lymph nodes were analyzed individually to determine a final stage classification based on the 2002 and 2010 International Union against Cancer system.

A total of 4,160 lymph nodes (median, 17; range, 0 to 49) were dissected for pathologic staging of the disease after histological examination of hematoxylin-eosin stained tissue sections.

The Institutional Review Board of Cancer Hospital, Chinese Academy of Medical Science approved this study. All patients or their guardians signed an informed consent form to participate in this study. The patients were followed-up regularly every 3 to 6 months after surgery or until death. The last follow-up was in December 2010, which included an esophagograph, chest radiograph, and ultrasound scan of the liver. Treatment failure was defined as any local or distant morphologic evidence of tumor.

For patients with tumor recurrence, treatments included any methods considered useful for relief of suffering. Until the end of follow-up, 77 patients had regional recurrence, and only 35 patients underwent salvage treatment (surgery, 10; radiotherapy, 25). Forty-one patients had organ metastasis; only 12 patients underwent salvage chemotherapy. The median duration of the follow-up time was 25 months (range, 6 to 280 months) after the esophagectomy; the mean duration was 36 months. Five patients were lost at the last follow-up. We counted these as deceased and there was no censure when we calculated overall survival (OS) and disease-free survival (DFS).

\section{Immunohistochemistry}

Tissue microarray sections were deparaffinized in xylene and rehydrated in an ethanol series to water. Antigen retrieval was performed in a citrate buffer $(0.01 \mathrm{M}, \mathrm{pH} 6.0)$ with a microwave-based method. After incubation with $20 \%$ normal serum, the sections were incubated with an anti-EGFR antibody (Novocastra, Cat: \#NCL-EGFR384, Newcastle Upon Tyne, UK) in a humidified chamber overnight at $4^{\circ} \mathrm{C}$. The next day, the sections were washed with phosphate buffered saline (PBS) three times, and further incubated using the PV-9000 Polymer Detection System (GBI Labs, cat: \#PV-9000, Mukilteo, WA, USA) and color-reacted with 3,3'-diaminobenzidine (DAB) solution (Zhongshan cat\# ZLI-9018, Beijing, China) as a chromogen.

Two experienced pathologists who were blinded to the clinical data reviewed the stained tissue sections. At least five microscopic fields were evaluated. The sections were scored for EGFR expression semiquantitatively based on the color and the percentage of epithelial cells showing membrane staining. The intensity was classified as follows: 0 , negative staining; 1 , weak staining; 2 , moderate staining; 3 , strong staining. The percent of positive cells was recorded as: 1,0 to $25 \%$; 2, 26 to $50 \% ; 3,51$ to $75 \%$;,$>75 \%$. A final score was achieved by multiplying the intensity $(0,1,2$, or 3$)$ and the percent of positive cells $(1,2,3$, or 4). For data analysis, scores $<8$ were defined as 'low expression' (Figure 1A), 
whereas scores with $\geq 8$ were considered 'high expression' (Figure 1B).

\section{Statistical analysis}

Categorical data were compared using the chi-squared test. The Kaplan-Meier method was used to construct OS and DFS curves, and the log-rank test was used to determine the statistical significance of differences. DFS was computed from the time of surgery to the time of clinical diagnosis of recurrent tumor, or death without evidence of disease recurrence, at which point the data were censored. OS was calculated from the time of surgery to the time of death from any cause, or to the time of last follow-up, at which point the data were censored. The prognostic significance of clinical and pathologic characteristics was determined using univariate Cox regression analysis. To assess the presence of possible confounding variables, a Cox regression model for multivariate analysis was applied

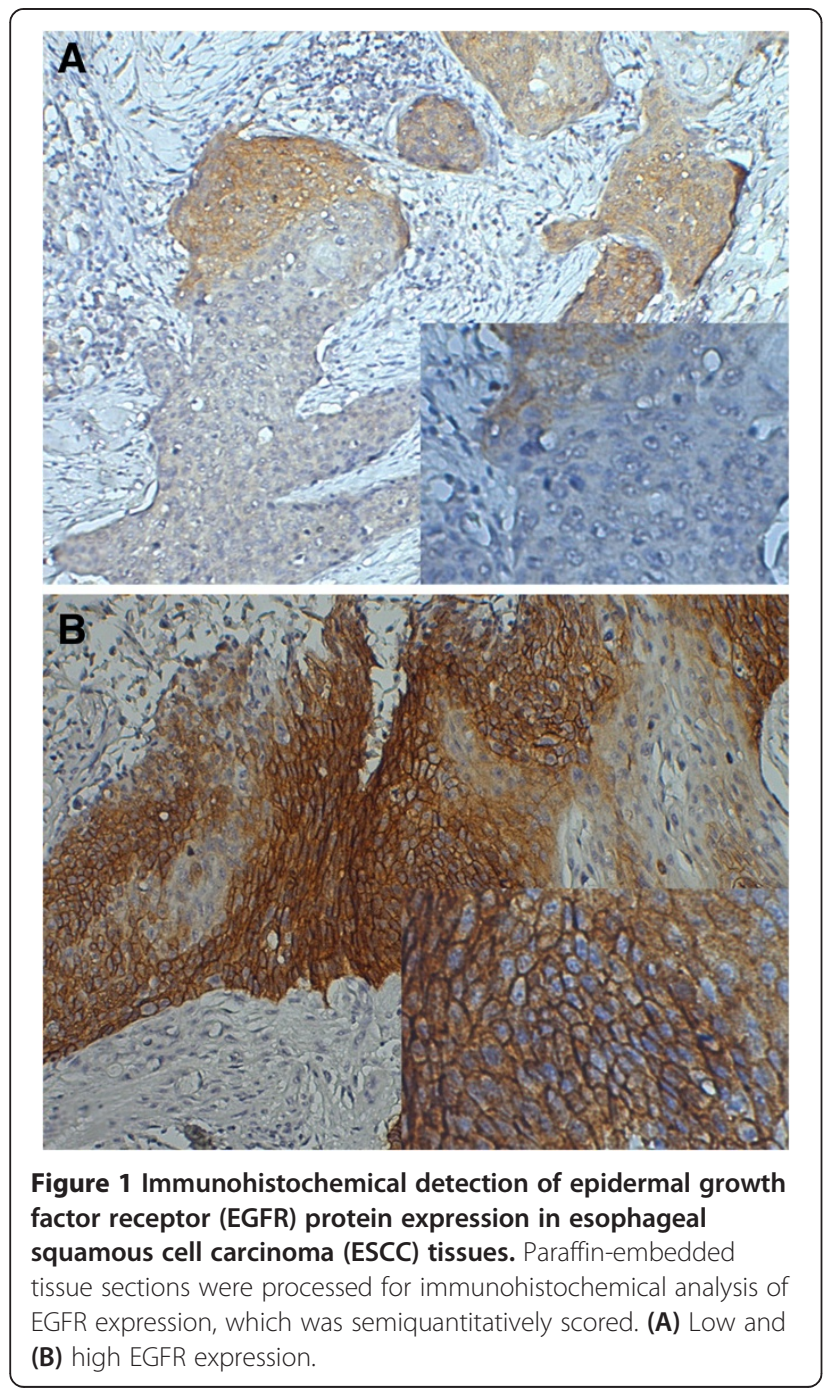

Table 1 Patient demographics, clinicopathological features, and epidermal growth factor receptor (EGFR) expression

\begin{tabular}{|c|c|c|c|c|c|c|}
\hline & \multicolumn{2}{|c|}{ EGFR -Total } & \multicolumn{2}{|c|}{ EGFR- Low } & \multicolumn{2}{|c|}{ EGFR- High } \\
\hline & $\bar{N}$ & $\%$ & $\bar{n}$ & $\%$ & $\bar{N}$ & $\%$ \\
\hline \multicolumn{7}{|l|}{ Gender } \\
\hline Male & 176 & 77.0 & 45 & 80.4 & 131 & 70.1 \\
\hline Female & 67 & 23.0 & 11 & 19.6 & 56 & 29.9 \\
\hline \multicolumn{7}{|l|}{ Age (y) } \\
\hline$<40$ & 12 & 4.9 & 4 & 7.17 & 8 & 4.3 \\
\hline 41 to 50 & 56 & 23.0 & 15 & 26.8 & 41 & 21.9 \\
\hline 51 to 60 & 101 & 41.6 & 21 & 37.5 & 80 & 42.8 \\
\hline 60 to 68 & 74 & 30.5 & 16 & 28.6 & 58 & 31.0 \\
\hline \multicolumn{7}{|l|}{ Length (cm) } \\
\hline$\leq 5.0$ & 130 & 53.5 & 32 & 57.1 & 98 & 52.4 \\
\hline 5.1 to 7.0 & 90 & 37.0 & 20 & 35.7 & 70 & 37.4 \\
\hline$>7.0$ & 23 & 9.5 & 4 & 7.1 & 19 & 10.2 \\
\hline \multicolumn{7}{|c|}{ Tumor location } \\
\hline Upper & 33 & 13.6 & 5 & 5.9 & 28 & 15.0 \\
\hline Middle & 155 & 63.8 & 42 & 75.0 & 113 & 60.4 \\
\hline Lower & 55 & 22.6 & 9 & 16.1 & 46 & 24.6 \\
\hline
\end{tabular}

Histological differentiation

$\begin{array}{lllllll}\text { Well } & 93 & 38.3 & 21 & 37.5 & 72 & 38.5 \\ \text { Moderate } & 124 & 51.0 & 27 & 48.2 & 97 & 51.9 \\ \text { Poor } & 26 & 10.7 & 8 & 14.3 & 18 & 9.6\end{array}$

Tumor invasion $P$ value $^{\mathrm{a}}$ 0.130

0.675

0.730

0.137

$\begin{array}{lllllll}\text { T2 } & 31 & 12.8 & 13 & 23.2 & 18 & 9.6\end{array}$

$\begin{array}{lllllll}\text { T3 } & 168 & 69.1 & 41 & 73.2 & 127 & 67.9\end{array}$

$\begin{array}{lllllll}\text { T4 } & 44 & 18.1 & 2 & 3.6 & 42 & 22.5\end{array}$

Lymph node status

0.002

$\begin{array}{lllllll}- & 130 & 53.5 & 40 & 71.4 & 90 & 48.1\end{array}$

$\begin{array}{lllllll}+ & 113 & 46.5 & 16 & 28.6 & 97 & 51.9\end{array}$

Number of LNM

$\begin{array}{lllllll}1 \text { to } 2 & 65 & 57.5 & 8 & 50.0 & 57 & 58.8 \\ 3 \text { to } 6 & 39 & 34.5 & 4 & 25.0 & 35 & 36.1 \\ \geq 7 & 9 & 8.0 & 4 & 25.0 & 5 & 5.2\end{array}$

Pathological stage (UICC, sixth edition)

$\begin{array}{lllllll}\text { IA } & 110 & 41.3 & 39 & 69.6 & 71 & 38.0 \\ \text { IIB } & 8 & 5.0 & 3 & 5.4 & 5 & 2.7 \\ \text { II } & 125 & 51.4 & 14 & 25.0 & 111 & 59.4\end{array}$

Pathological stage (UICC, seventh edition)

$\begin{array}{lllllll}\text { IB } & 23 & 9.5 & 10 & 17.9 & 13 & 7.0 \\ \text { IIA } & 87 & 35.8 & 29 & 51.8 & 58 & 31.0 \\ \text { IIB } & 5 & 2.1 & 1 & 1.8 & 4 & 2.1 \\ \text { IIIA } & 68 & 28.0 & 7 & 12.5 & 61 & 32.6 \\ \text { IIIB } & 28 & 11.5 & 4 & 7.1 & 24 & 12.8 \\ \text { IIIC } & 32 & 13.2 & 5 & 8.9 & 27 & 14.4\end{array}$

${ }^{\mathrm{a}} \mathrm{P}, \mathrm{P}$ values were calculated by using chi-square. 
for factors that achieved significance in the univariate analysis. All statistical analyses were performed using SPSS software (version 13.0 for Windows; SPSS, Chicago, IL, USA). Kaplan-Meier survival curves were drawn with GraphPad Prism (version 5.0 for Windows; GraphPad Software, San Diego, CA, USA). A 2-sided significance level of $P<0.05$ was considered statistically significant.

\section{Results}

Expression of epidermal growth factor receptor protein in esophageal squamous cell carcinoma tissue specimens

We retrieved tissue samples from each of the 243 ESCC patients and immunostained these tissue sections for EGFR expression. Our data showed that in 187 of the 243 cases $(77.0 \%)$ high levels of EGFR protein were observed in ESCC tissues, while in the remaining cases EGFR levels were nil or low. We then investigated correlations between EGFR expression and clinicopathological data from the patients and found that EGFR expression was associated with advanced tumor stage $(P=0.001)$, tumor lymph node metastasis $(P=0.002)$, and higher pathological stages (UICC 2002 and 2010, $P<0.001$ ). However, EGFR expression was not associated with age, gender, tumor location, size of the tumor lesion, or histological differentiation (Table 1).

\section{Association of epidermal growth factor receptor expression with overall survival of esophageal squamous cell carcinoma patients}

We investigated correlations between EGFR expression in resected ESCC tissues and survival of ESCC patients and found that the 5-year OS and DFS rates of patients with EGFR expression were $15.0 \%$ and $14.4 \%$, respectively, and the median survival times were 16.0 months and 11.6 months. In contrast, the 5-year OS and DFS rates for patients with no or low EGFR expression in ESCC tissues were $39.3 \%$ and $37.5 \%$, respectively, and the median survival times were 31.7 and 25.7 months (Figure 2A,B). The differences in OS and DFS between these two groups are statistically significant $(P<0.0001$, both $)$.

Univariate and multivariate analysis of overall survival and disease-free survival of esophageal squamous cell carcinoma patients

To identify the important prognostic factors for ESCC, we performed univariate and multivariate analyses. The univariate analysis data showed that tumor size, pathological tumor stage, positive lymph nodes, tumor-node-metastasis (TNM) stage (UICC, sixth or seventh edition), and EGFR expression all affected the OS and DFS of the patients (Table 2). The multivariate analysis further showed that histological grade, positive lymph nodes, tumor size and EGFR expression were independent prognostic factors for OS and DFS of these patients (Table 3).

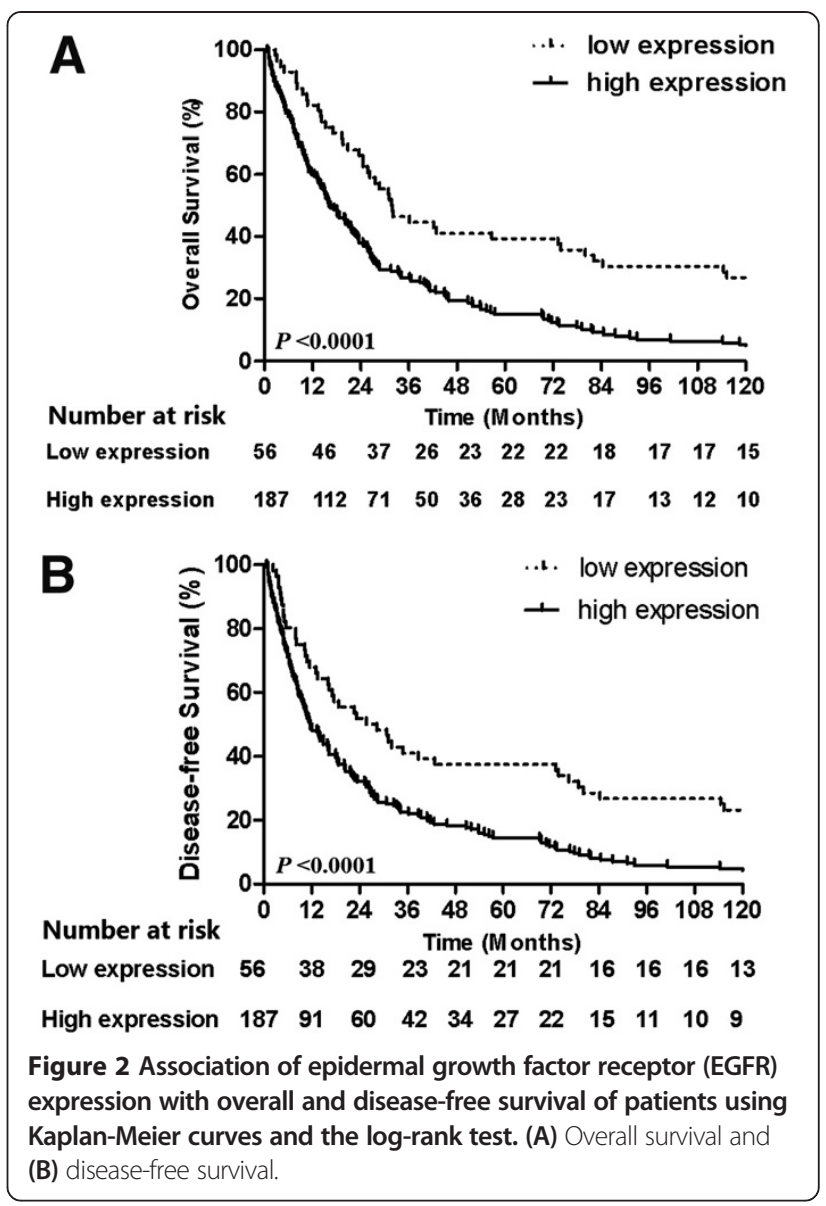

Subgroup analyses of epidermal growth factor receptor expression and overall survival of patients

To further confirm the usefulness of EGFR as a prognostic factor, we compared subgroups of patients who tested either negative or positive for metastasis in lymph nodes (130 and 113 patients, respectively). In the negative lymph node group, the 5-year OS (DFS) rate was $28.9 \%$ (24.0\%) in patients who expressed EGFR, and $50.0 \%$ (47.5\%) for patients with low levels or no EGFR expression $(P=0.002$ $(P=0.001))$. However, in the 113 cases with positive lymph nodes, the 5-year OS rates were $5.2 \%$ for patients with high EGFR expression, and $12.5 \%$ for those with low expression $(P=0.067)$.

For the 110 patients with stage T2-3N0M0 IIA disease (2002 UICC), the 5-year OS (DFS) rate was $29.6 \%(28.0 \%)$ for those with high-EGFR expression, and $48.7 \%(46.7 \%)$ for those with low-EGFR expression $(P=0.010(P=0.007))$. Furthermore, in 87 cases of patients with stage T3N0MO IIA (UICC seventh edition) disease, the 5-year OS rate for patients with high EGFR expression was significantly lower than those with low EGFR expression (29.3\% compared with 48.3\%; $P=0.026$ ). 
Table 2 Univariate analysis of disease-free survival (DFS) and overall survival (OS) of esophageal squamous cell carcinoma (ESCC) patients

\begin{tabular}{|c|c|c|c|c|c|c|c|}
\hline & \multirow[t]{2}{*}{$\mathbf{N}$} & \multicolumn{3}{|c|}{ Disease-free survival } & \multicolumn{3}{|c|}{ Overall survival } \\
\hline & & $\mathrm{HR}$ & $95 \% \mathrm{Cl}$ & $P$ value & HR & $95 \% \mathrm{Cl}$ & $P$ value \\
\hline \multicolumn{8}{|l|}{ Gender } \\
\hline Male (ref) & 176 & 1 & & & 1 & & \\
\hline Female & 67 & 1.202 & 0.894 to 1.616 & 0.222 & 1.223 & 0.906 to 1.650 & 0.188 \\
\hline Age (y) & & & & 0.154 & & & 0.178 \\
\hline$<40$ (ref) & 12 & 1 & & & 1 & & \\
\hline 41 to 50 & 56 & 0.531 & 0.265 to 1.066 & 0.075 & 0.559 & 0.278 to 1.121 & 0.101 \\
\hline 51 to 60 & 101 & 0.720 & 0.500 to 1.037 & 0.078 & 0.716 & 0.496 to 1.035 & 0.075 \\
\hline 60 to 68 & 74 & 0.857 & 0.631 to 1.164 & 0.324 & 0.875 & 0.643 to 1.190 & 0.395 \\
\hline Length (cm) & & & & 0.008 & & & 0.011 \\
\hline$\leq 5.0$ (ref) & 130 & 1 & & & 1 & & \\
\hline 5.1 to 7.0 & 90 & 0.546 & 0.345 to 0.864 & 0.100 & 0.563 & 0.356 to 0.890 & 0.014 \\
\hline$>7.0$ & 23 & 0.762 & 0.477 to 1.218 & 0.256 & 0.781 & 0.488 to 1.248 & 0.301 \\
\hline Tumor location & & & & 0.104 & & & 0.204 \\
\hline Upper (ref) & 33 & 1 & & & 1 & & \\
\hline Middle & 155 & 1.611 & 1.029 to 2.520 & 0.037 & 1.502 & 0.961 to 2.349 & 0.075 \\
\hline Lower & 55 & 1.280 & 0.925 to 1.772 & 0.136 & 1.166 & 0.842 to 1.615 & 0.354 \\
\hline Histological differentiation & & & & 0.012 & & & 0.325 \\
\hline Well & 93 & 1 & & & 1 & & \\
\hline Moderate & 124 & 1.418 & 1.064 to 1.891 & 0.017 & 1.296 & 0.972 to 1.727 & 0.077 \\
\hline Poor & 26 & 1.271 & 1.059 to 1.526 & 0.010 & 1.247 & 1.039 to 1.497 & 0.018 \\
\hline \multicolumn{8}{|l|}{ EGFR expression } \\
\hline Low (ref) & 56 & 1 & & & 1 & & \\
\hline High & 187 & 1.974 & 1.413 to 2.758 & $<0.0001$ & 2.075 & 1.485 to 2.899 & $<0.0001$ \\
\hline Tumor stage & & & & $<0.0001$ & & & $<0.0001$ \\
\hline T2 (ref) & 31 & 1 & & & 1 & & \\
\hline T3 & 168 & 1.303 & 0.874 to 1.940 & 0.192 & 1.320 & 0.886 to 1.967 & 0.170 \\
\hline T4 & 44 & 1.468 & 1.146 to 1.880 & 0.002 & 1.532 & 1.194 to 1.965 & 0.002 \\
\hline \multicolumn{8}{|l|}{ N stage ${ }^{a}$} \\
\hline NO (ref) & 130 & 1 & & & 1 & & \\
\hline N1 & 113 & 2.203 & 1.676 to 2.897 & $<0.001$ & 2.267 & 1.723 to 2.983 & $<0.001$ \\
\hline Stage $e^{a}$ & & & & $<0.0001$ & & & $<0.0001$ \\
\hline IIA (ref) & 110 & 1 & & & 1 & & \\
\hline$\| \mathrm{B}$ & 8 & 1.343 & 0.650 to 2.776 & 0.640 & 1.253 & 0.607 to 2.585 & 0.541 \\
\hline III & 125 & 1.539 & 1.336 to 1.771 & $<0.0001$ & 1.583 & 1.373 to 1.824 & $<0.0001$ \\
\hline$N$ stage $^{b}$ & & & & $<0.0001$ & & & $<0.0001$ \\
\hline No (ref) & 130 & 1 & & & 1 & & \\
\hline N1 & 65 & 1.833 & 1.339 to 2.509 & $<0.0001$ & 1.882 & 1.374 to 2.578 & $<0.0001$ \\
\hline N2 & 39 & 1.682 & 1.384 to 2.044 & $<0.0001$ & 1.756 & 1.442 to 2.138 & $<0.0001$ \\
\hline N3 & 9 & 1.701 & 1.338 to 2.161 & $<0.0001$ & 1.532 & 1.210 to 1.940 & $<0.0001$ \\
\hline Stage ${ }^{b}$ & & & & $<0.0001$ & & & $<0.0001$ \\
\hline IB (ref) & 23 & 1 & & & 1 & & \\
\hline$\| A$ & 87 & 0.969 & 0.596 to 1.576 & 0.899 & 0.939 & 0.577 to 1.529 & 0.801 \\
\hline
\end{tabular}


Table 2 Univariate analysis of disease-free survival (DFS) and overall survival (OS) of esophageal squamous cell carcinoma (ESCC) patients (Continued)

\begin{tabular}{clllllll}
\hline IIB & 5 & 0.971 & 0.590 to 1.599 & 0.908 & 0.908 & 0.555 to 1.486 & 0.702 \\
IIA & 68 & 1.283 & 1.082 to 1.523 & 0.003 & 1.289 & 1.086 to 1.529 & 0.003 \\
IIB & 28 & 1.386 & 1.168 to 1.644 & $<0.0001$ & 1.433 & 1.203 to 1.708 & $<0.0001$ \\
IIC & 32 & 1.280 & 1.123 to 1.458 & $<0.0001$ & 1.306 & 1.145 to 1.489 & 0.967 \\
\hline
\end{tabular}

$\mathrm{HR}$, hazard ratio; $\mathrm{Cl}$, confidence interval; $P$ value was calculated by using a log-rank test; ref, reference.

aUICC, sixth edition.

bUICC, seventh edition.

\section{Discussion}

EGFR overexpression has been reported previously in 40 to $84 \%$ of esophageal cancer tissues [19-21]. Significant associations have been found between the level of EGFR expression and some clinicopathological characteristics, including tumor differentiation, tumor stage, lymph node status, and UICC TNM stages [19,22,23]. However, whether or not EGFR expression is associated with the survival of esophageal cancer patients remains controversial. Several researchers have shown that EGFR overexpression was associated with poor OS and DFS of esophageal cancer patients [22-24], whereas others have demonstrated that EGFR overexpression had no association with either survival rates $[25,26]$. These inconsistent conclusions drawn from different studies may be due to an insufficient number of cases or duration of follow-up, or the methods used to detect EGFR expression.

In the present study, we retrospectively retrieved ESCC tissue specimens from 243 patients, which had been collected from 1980 to 1997, and followed these patients for more than 13 years. Moreover, with these specimens we performed standard immunohistochemistry using an anti-EGFR monoclonal antibody from Novocastra, an international company with an excellent reputation for providing immunohistochemistry-quality antibodies, to provide more informative data. We found that EGFR protein was highly expressed in $77 \%$ of these tissue specimens. High EGFR expression was associated with tumor invasion, lymph node metastasis, numbers of lymph node metastases, and UICC 2002 and 2010 TNM stages in these esophageal cancer patients. These data are consistent with previous studies [19,22,23]. More importantly, OS and DFS rates were significantly lower in patients with high EGFR expression than in patients with little or no EGFR expression. Further multivariate analysis showed that EGFR expression is an independent prognostic factor for ESCC patients. A future study will investigate how the EGFR signaling pathway contributes to esophageal cancer progression or chemotherapy resistance in ESCC patients.

Until now, pathological features of ESCC such as tumor stage, lymph node status, and tumor distant metastasis have been widely used as prognostic or chemotherapy indicators in addition to more detailed subgroup staging. The latter staging system may better predict prognosis since it is not uncommon that prognosis differs even in patients with the same clinical stage. For instance, the 5-year OS rate of patients with stage IIa disease (according to UICC 2002, T2-3NOM0) after esophagectomy was about 50\%, and the remaining patients died within five years because of tumor recurrence or metastasis. Rice et al. [7] showed that the 5-year OS rate was about $60 \%$ for T2N0M0 esophageal cancer and about 50\% for T3NOM0, a difference that is statistically significant. Subsequently, stage IIa disease (UICC 2002), which includes T2N0M0 and T3NOM0, was changed to Ib (T2NOM0) and IIa (T3NOM0) in the UICC 2009 edition.

In the current study the 5-year OS rates of T2N0M0 and T3N0M0 diseases were $39.1 \%$ and $35.6 \%$, respectively, a difference that was not statistically significant $(P=0.801)$. However, in the same group of patients, the levels of EGFR expression (that is, high levels compared with low) significantly influenced both the 5-year OS and DFS rates. This

Table 3 Multivariate Cox regression analysis of disease-free survival (DFS) and overall survival (OS)

\begin{tabular}{|c|c|c|c|c|}
\hline & Overal & & Disease-f & \\
\hline & $\mathrm{HR}(95 \% \mathrm{Cl})$ & $P$ value & $\mathrm{HR}(95 \% \mathrm{Cl})$ & $P$ value \\
\hline Histological grade & 1.804 (1.282 to 2.540$)$ & 0.062 & 1.301 (1.060 to 1.597$)$ & 0.012 \\
\hline Tumor stage & 1.191 (0.797 to 1.778$)$ & 0.394 & $1.178(0.790$ to 1.758$)$ & 0.422 \\
\hline Lymph node status & 2.028 (1.529 to 2.688 ) & $<0.0001$ & 1.888 (1.423 to 2.504$)$ & $<0.0001$ \\
\hline EGFR expression & 1.804 (1.282 to 2.504$)$ & 0.001 & 1.681 (1.192 to 2.369$)$ & 0.003 \\
\hline Tumor size (length) & 1.331 (1.090 to 1.625$)$ & 0.005 & 1.334 (1.093 to 1.627$)$ & 0.005 \\
\hline
\end{tabular}

$\mathrm{HR}$, hazard ratio; $\mathrm{Cl}$, confidence interval; EGFR, epidermal growth factor receptor. 
suggests that EGFR is a useful biomarker and provides a precise tool for prediction of survival of esophageal cancer patients. Use of EGFR expression could contribute to staging and a more accurate prognostic prediction compared with UICC staging alone, especially for patients with stage T2/T3N0M0. Furthermore, our current multivariate analysis showed that EGFR expression and lymph node status were independent prognostic factors to predict survival of esophageal cancer patients, whereas tumor stage was not able to predict survival. These results suggest that tumor stage alone was not as sensitive as EGFR and lymph node status in predicting the prognosis of patients.

EGFR is the cell-surface receptor for members of the epidermal growth factor family. It is activated by binding to its specific ligands, including epidermal growth factor (EGF) and transforming growth factor $\alpha$ (TGF $\alpha$ ). This binding then activates downstream gene pathways such as the mitogen-activated protein kinase (MAPK), protein kinase B (Akt), and c-Jun N-terminal kinase (JNK) pathways, to lead to DNA synthesis and cell proliferation, migration, and invasion [27]. Clinically, EGFR mutation and aberrant overexpression may lead to human carcinogenesis and tumor progression, including esophageal cancer [14]. For the past decade, targeting EGFR activity using gefitinib and erlotinib has been used successfully to treat certain lung and colorectal cancer patients [28]. Thus, such treatment may extend to esophageal cancer patients with high EGFR expression and provide a survival benefit.

\section{Conclusions}

In summary, in the present study we found that EGFR expression was associated with tumor invasion, lymph node status, number of lymph node metastases, and UICC TNM staging in ESCC patients. This study also showed that the OS and DFS rates were significantly lower in ESCC patients with high EGFR expression than in those with low EGFR expression. The multivariate analysis indicated that EGFR expression and lymph node metastasis were independent factors for predicting ESCC prognosis. Furthermore, ESCC patients at stage T2-3NOMO could be considered to have better or poor prognosis based on the EGFR expression level in tissues. Therefore, our current data suggest that EGFR expression should be included as a supplement to UICC staging, especially for T2/T3NOM0 and lymph node-negative patients.

\section{Abbreviations \\ DFS: Disease-free survival; EGFR: Epidermal growth factor receptor; \\ ESCC: Esophageal squamous cell carcinoma; OS: Overall survival; \\ TNM: Tumor-node-metastasis; UICC: Union for international cancer control.}

\section{Competing interests}

There is no conflict of interest involved in this work.

\section{Authors' contributions}

$H J$ and $X Z$ designed the study, with assistance from ZH, ZX, LX, ZW, SK, WL, $X N$. WQ and $Z \mathrm{H}$ analyzed the data. All authors helped to interpret the findings. WQ and $X Z$ wrote the manuscript, which was approved by all authors. All authors read and approved the final manuscript.

\section{Acknowledgements}

We thank Professor Xiaohui Lin for editing the manuscript.

This work was supported by: Capital Foundation for Medical Research and Development (2007-2012); National Natural Science Foundation (81021061); National Natural Science Foundation (39925020).

\section{Author details}

${ }^{1}$ Department of Radiation Oncology, Cancer Institute and Hospital, Chinese Academy of Medical Sciences (CAMS) and Peking Union Medical College (PUMC), No.17, Nanli, Panjiayuan, Beijing 100021, People's Republic of China. ¿Laboratory of Cellular and Molecular Biology, Cancer Institute and Hospital, Chinese Academy of Medical Sciences (CAMS) and Peking Union Medical

College (PUMC), No.17, Nanli, Panjiayuan, Beijing 100021, People's Republic of China. ${ }^{3}$ Department of Pathology, Cancer Institute and Hospital, Chinese Academy of Medical Sciences (CAMS) and Peking Union Medical College (PUMC), No.17, Nanli, Panjiayuan, Beijing 100021, People's Republic of China. ${ }^{4}$ Department of Thoracic Surgery, Cancer Institute and Hospital, Chinese Academy of Medical Sciences (CAMS) and Peking Union Medical College (PUMC), No.17, Nanli, Panjiayuan, Beijing 100021, People's Republic of China. ${ }^{5}$ Present working address: Department of Radiation Oncology, Sichuan Cancer Hospital, No.55, Fourth Section, Renmin South Road, Chengdu 610041, People's Republic of China.

Received: 17 April 2013 Accepted: 6 October 2013

Published: 16 October 2013

\section{References}

1. Chen W, Zeng H, Zheng R, Zhang S, He J: Cancer incidence and mortality in China, 2007. Chin J Cancer Res 2012, 24:1-8.

2. Jemal A, Bray F, Center MM, Ferlay J, Ward E, Forman D: Global cancer statistics. CA Cancer J Clin 2011, 61:69-90.

3. Bancewicz J, Clark P, Smith D, Donnelly R, Fayers P, Weeden S, Girling D, Hutchinson T, Harvey A, Lyddiard J, Al-Jilaihawi A, Bown S, Cottier B, Jeyasingham K, Lea R, Matthews H, Moghissi K, Morritt G, Myskow M, Pagliero K, Rowland C, Yosef H, Med Res Council Oesophageal Canc: Surgical resection with or without preoperative chemotherapy in esophageal cancer: a randomised controlled trial. Lancet 2002, 359:1727-1733.

4. Kelsen DP, Ginsberg R, Pajak TF, Sheahan DG, Gunderson L, Mortimer J, Estes N, Haller DG, Ajani J, Kocha W, Minsky BD, Roth JA: Chemotherapy followed by surgery compared with surgery alone for localized esophageal cancer. N Engl J Med 1998, 339:1979-1984.

5. Xiao ZF, Yang ZY, Miao YJ, Wang LH, Yin WB, Gu XZ, Zhang DC, Sun KL, Chen GY, He J: Influence of number of metastatic lymph nodes on survival of curative resected thoracic esophageal cancer 7.patients and value of radiotherapy: report of 549 cases. Int J Radiat Oncol Biol Phys 2005, 62:82-90.

6. Kawahara K, Maekawa T, Okabayashi K, Shiraishi T, Yoshinaga Y, Yoneda S, Hideshima T, Shirakusa T: The number of lymph node metastases influences survival in esophageal cancer. J Surg Oncol 1998, 67:160-163.

7. Rice TW, Rusch WW, Apperson-Hansen C, Allen MS, Chen LQ, Hunter JG, Kesler KA, Law S, Lerut TE, Reed CE, Salo JA, Scott WJ, Swisher SG, Watson TJ, Blackstone EH: Worldwide esophageal cancer collaboration. Dis Esophagus 2009, 22:1-8

8. Sobin LCW, Wittekind C, International Union Against Cancer (UICC): TNM Classification of Malignant Tumours. 6th edition. New York: John Wiley and Sons; 2002.

9. Sobin LH, Gospodarowicz MK, Wittekind C, International Union Against Cancer (UICC): TNM Classification of Malignant Tumours. 7th edition. New York: Wiley-Liss; 2010.

10. Gorski DH, Beckett MA, Jaskowiak NT, Calvin DP, Mauceri HJ, Salloum RM, Seetharam S, Koons A, Hari DM, Kufe DW, Weichselbaum RR: Blockage of the vascular endothelial growth factor stress response increases the antitumor effects of ionizing radiation. Cancer Res 1999, 59:3374-3378.

11. Kanamori A, Abe Y, Yajima Y, Manabe $Y$, Ito K: Epidermal growth factor receptors in plasma membranes of normal and diseased human thyroid glands. J Clin Endocrinol Metab 1989, 68:899-903. 
12. Hoos A, Urist MJ, Stojadinovic A, Mastorides S, Dudas ME, Leung DH, Kuo D, Brennan MF, Lewis JJ, Cordon-Cardo C: Validation of tissue microarrays for immunohistochemical profiling of cancer specimens using the example of human fibroblastic tumors. Am J Pathol 2001, 158:1245-1251.

13. Mayer A, Takimoto M, Fritz E, Schellander G, Kofler K, Ludwig H: The prognostic significance of proliferating cell nuclear antigen, epidermal growth factor receptor, and mdr gene expression in colorectal cancer. Cancer 1993, 71:2454-2460.

14. Nicholson Rl, Gee JM, Harper ME: EGFR and cancer prognosis. Eur J Cancer 2001, 37(Suppl 4):S9-S15.

15. Perez EA: The role of adjuvant monoclonal antibody therapy for breast cancer: rationale and new studies. Curr Oncol Rep 2001, 3:516-522.

16. Gibault L, Metges JP, Conan-Charlet V, Lozac'h P, Robaszkiewicz M, Bessaguet C, Lagarde N, Volant A: Diffuse EGFR staining is associated with reduced overall survival in locally advanced oesophageal squamous cell cancer. Br J Cancer 2005, 93:107-115.

17. Yano H, Shiozaki H, Kobayashi K, Yano T, Tahara H, Tamura S, Mori T: Immunohistologic detection of the epidermal growth factor receptor in human esophageal squamous cell carcinoma. Cancer 1991, 67:91-98.

18. Siegel R, Ahmedin Jemal D: Cancer Facts \& Figures. Atlanta: American Cancer Society, Inc:; 2013.

19. Hanawa M, Suzuki S, Dobashi Y, Yamane T, Kono K, Enomoto N, Ooi A: EGFR protein overexpression and gene amplification in squamous cell carcinomas of the esophagus. Int J Cancer 2006, 118:1173-1180.

20. Miyawaki M, Hijiya N, Tsukamoto Y, Nakada C, Kawahara K, Moriyama M: Enhanced phosphorylation of the epidermal growth factor receptor at the site of tyrosine 992 in esophageal carcinomas. APM/S 2008, 116:1097-1106.

21. Boone J, van Hillegersberg R, Offerhaus GJ, van Diest PJ, Borel Rinkes IH, Ten Kate FJ: Targets for molecular therapy in esophageal squamous cell carcinoma: an immunohistochemical analysis. Dis Esophagus 2009, 22:496-504

22. Wang KL, Wu TT, Choi IS, Wang H, Resetkova E, Correa AM, Hofstetter WL, Swisher SG, Ajani JA, Rashid A, Albarracin CT: Expression of epidermal growth factor receptor in esophageal and esophagogastric junction adenocarcinomas: association with poor outcome. Cancer 2007, 109:658-667.

23. Wilkinson NW, Black JD, Roukhadze E, Driscoll D, Smiley S, Hoshi H, Geradts J, Javle M, Brattain M: Epidermal growth factor receptor expression correlates with histologic grade in resected esophageal adenocarcinoma. J Gastrointest Surg 2004, 8:448-453.

24. Hoshino M, Fukui H, Ono Y, Sekikawa A, Ichikawa K, Tomita S, Imai Y, Imura J, Hiraishi H, Fujimori T: Nuclear expression of phosphorylated EGFR is associated with poor prognosis of patients with esophageal squamous cell carcinoma. Pathobiology 2007, 74:15-21.

25. Gotoh M, Takiuchi H, Kawabe S, Ohta S, Kii T, Kuwakado S, Katsu K Epidermal growth factor receptor is a possible predictor of sensitivity to chemoradiotherapy in the primary lesion of esophageal squamous cell carcinoma. Jpn J Clin Oncol 2007, 37:652-657.

26. Kii T, Takiuchi H, Kawabe S, Gotoh M, Ohta S, Tanaka T, Kuwakado S, Nishitani $\mathrm{H}$, Katsu K: Evaluation of prognostic factors of esophageal squamous cell carcinoma (stage II-III) after concurrent chemoradiotherapy using biopsy specimens. Jpn J Clin Oncol 2007, 37:583-589.

27. Oda K, Matsuoka Y, Funahashi A, Kitano H: A comprehensive pathway map of epidermal growth factor receptor signaling. Mol Syst Biol 2005, 1:2005 0010

28. Paez JG, Janne PA, Lee JC, Tracy S, Greulich H, Gabriel S, Herman P, Kaye FJ, Lindeman N, Boggon TJ, Naoki K, Sasaki H, Fujii Y, Eck MJ, Sellers WR, Johnson BE, Meyerson M: EGFR mutations in lung cancer: correlation with clinical response to gefitinib therapy. Science 2004, 304:1497-1500.

\section{doi:10.1186/1477-7819-11-278}

Cite this article as: Wang et al:: Expression of epidermal growth factor receptor is an independent prognostic factor for esophageal squamous cell carcinoma. World Journal of Surgical Oncology 2013 11:278.

\section{Submit your next manuscript to BioMed Central and take full advantage of:}

- Convenient online submission

- Thorough peer review

- No space constraints or color figure charges

- Immediate publication on acceptance

- Inclusion in PubMed, CAS, Scopus and Google Scholar

- Research which is freely available for redistribution

Submit your manuscript at www.biomedcentral.com/submit
Biomed Central 